\title{
edificio de asistencia social de la CIBA Basilea
}

SUTER Y SUTER, arquitectos

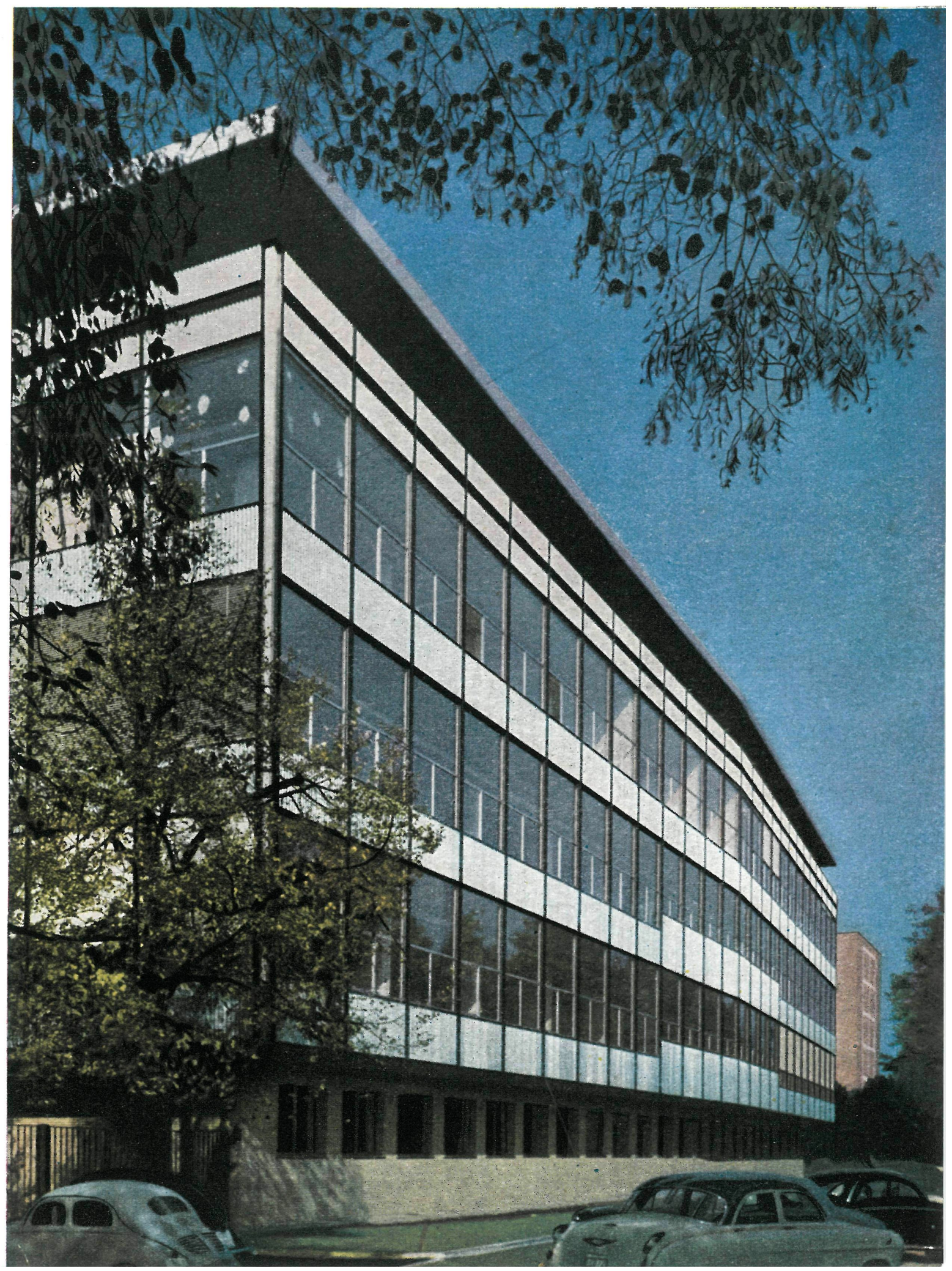


Cada vez se hace más frecuente la construcción de edificios destinados a una función social-comedores, salas de conferencias y proyecciones, salones de exposiciones-dentro del programa orgánico de las grandes industrias. Esto, sin duda, contribuye poderosamente a la confraternización del personal que, así, trabaja, come y se distrae en unión de sus jefes y de sus compañeros.

La nueva cantina de la Ciba, en Basilea, está construida con gran lujo de amplitud espacial, dotada de toda suerte de instalaciones modernas y decorada-interior $\mathrm{y}$ exteriormente-con exquisito cuidado y buen gusto. Próximo al edificio hay un parque público, con viejos árboles, con el que forma una composición pintoresca y agradable.

La estructura sustentante es de hormigón armado. Consiste ésta en una serie de pórticos dispuestos perpendicularmente a las dos fachadas principales. Las plantas altas vuelan sobre la baja y, de este modo, pueden conseguirse unos alzados graciosos, ligeros y de impresión flotante, ya que los cerramientos no tienen misión resistente y pueden ser tratedos con absoluta libertad. Asi, pues, todo ser tracos codo red edicio presenta undes ronas acristaladas, bandas rado, a base de grandes zonas acristaladas, bandas res Ciba.

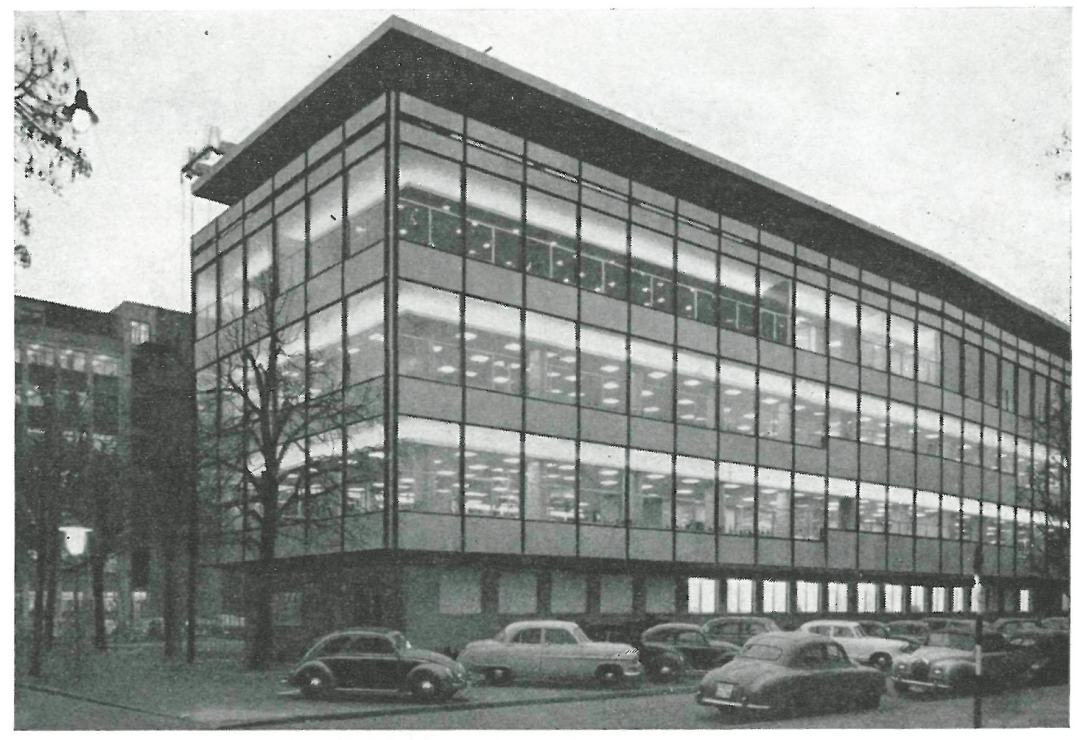

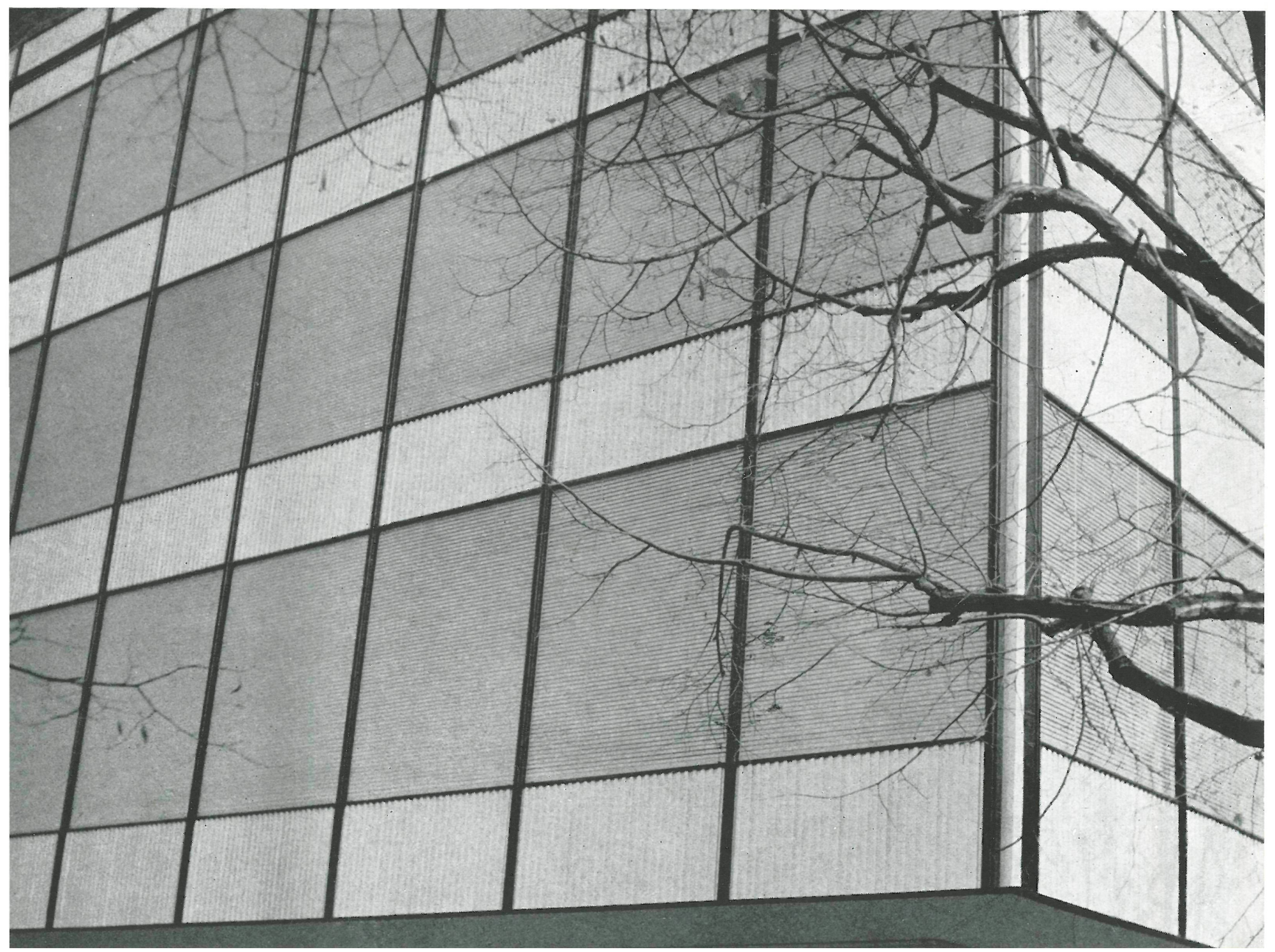




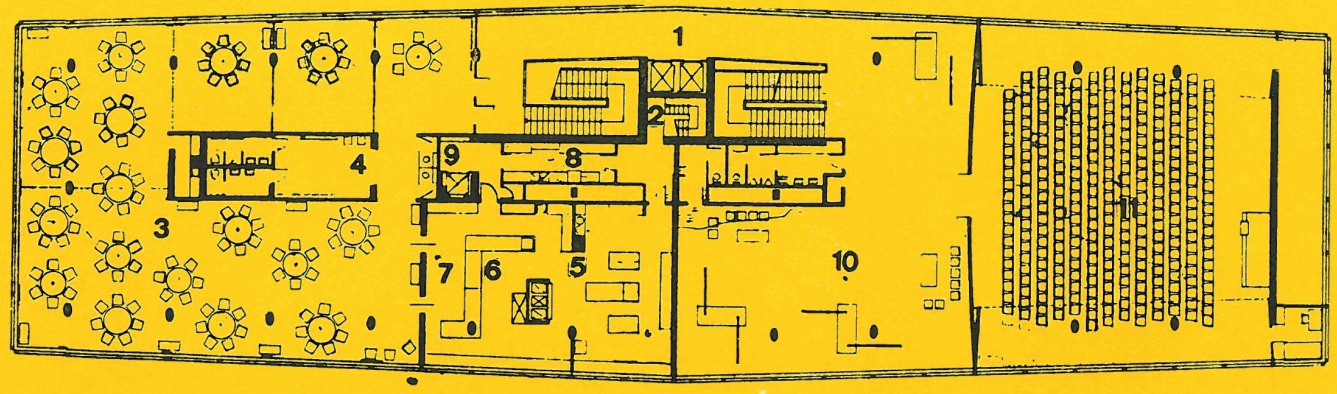

tercera

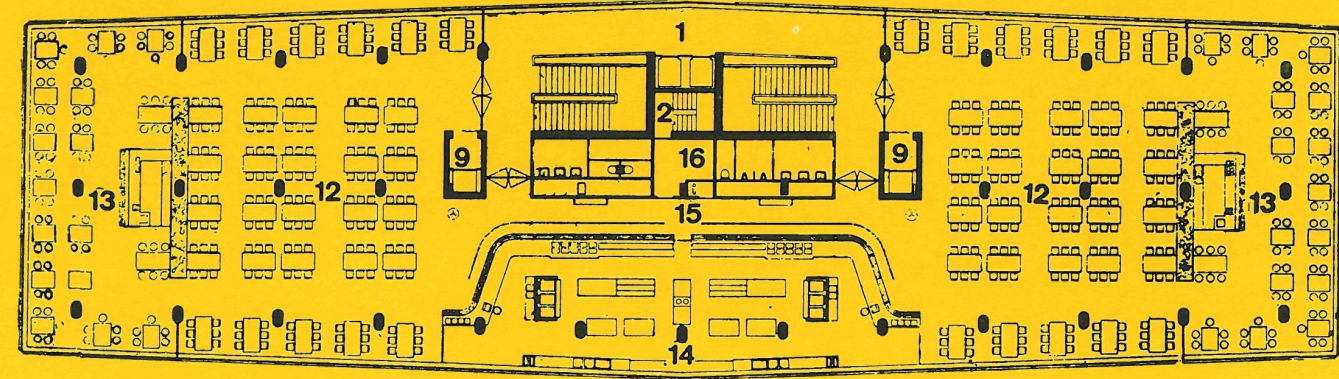

primera y segunda

1. Caja de escaleras.-2. Escalera de servicio. -3 . plazas. - 4. Vestuario aseos.-5. Cocina con montaplatos. - 6. Oficio. -7 . Buffet.-8. Fregadero. -9 . Montacargas. - 10. Salon de exposiciones.-11. Sala de conferencias. -12 . Comedor de empleados. -13 . colo $\mathrm{y}$ frear. 14 . ra de autoservicio. 16 . . 18. Vestuarios aseos y al. binas telefónicas - 19 . Cocina -19 a. Cocinero-mesa caliente y hornos - 20 . Preparación -20 as. Máquina peladora de patatas y lavaplatos.-20b. Recipientes de legumbres.21. Provisiones cotidianas 2. Camaras frigoríficas. 23. Buffet frío.-24. Recepción de mercancias y sala de espera.-25. Entrada. - 26. Montacargas del sótano.-27. Escalera del sotano. 28 . Oficina.29. Comedor de personal. 30. Lavadero. - 31 . Pasteleria. 32. Comedor de desayunos. Com. Entrada 34. Ziosco 35. Garaje de bicicletas -36 . Gastuario de cabalieros - -37 Ves tuario de señoras - 38 . tículos de consumo- -39 . Habitación de repasado. 40. Budega para patatas. 41. Bodega para bebidas. 42. Maquinaria. -43. Equipo eléctrico y sala de almacenaje.-44. Cámara de climatización.-45. Depósito. -46 . Cubierto

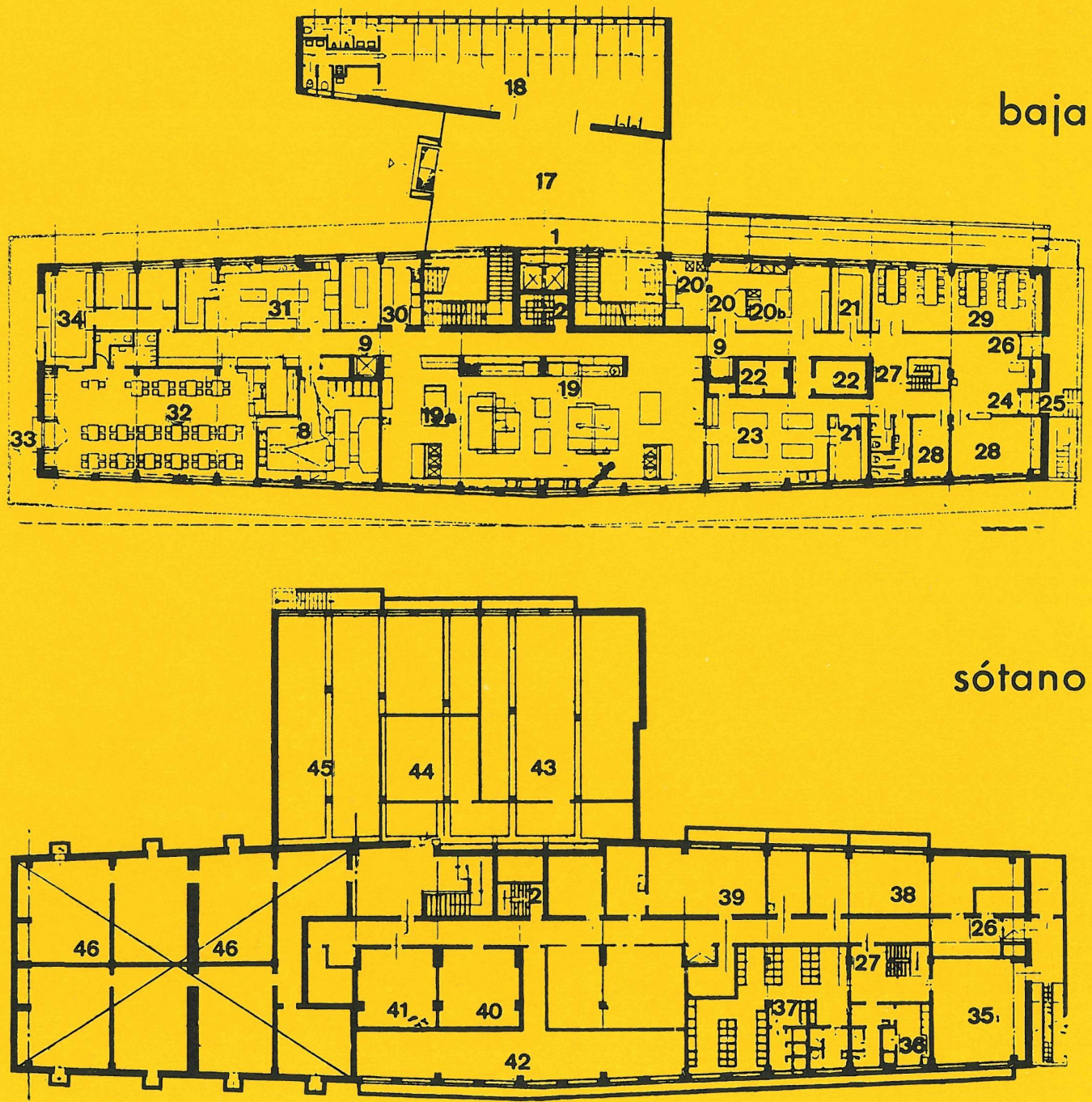




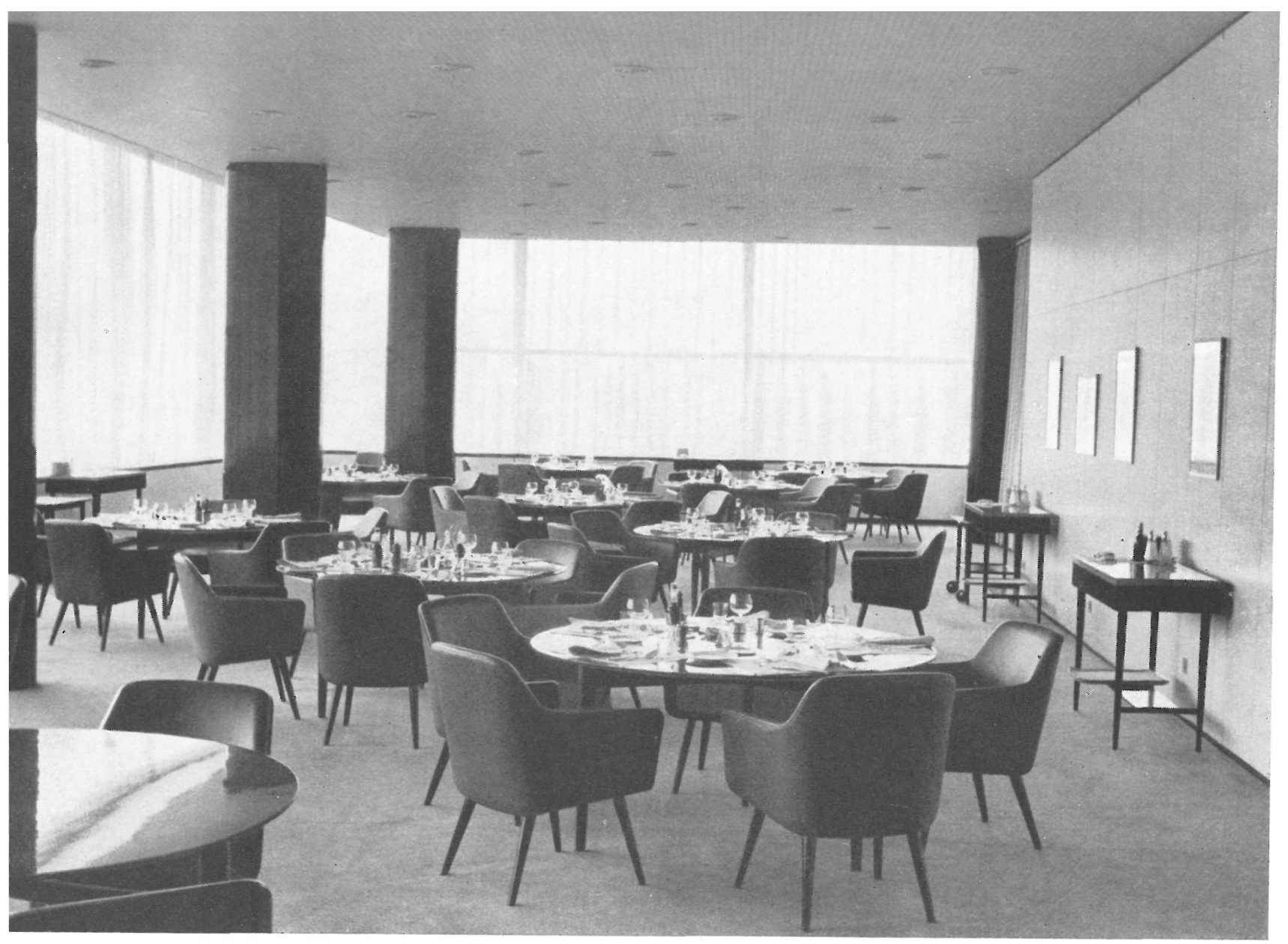

La planta baja comprende el vestíbulo y vestuarios-en un cuerpo de edificio de una sola planta y forma graciosanente in medor de desayunos e instalaciones completisimas de cocina.

En el sótano se disponen los almacenes, garaje de bicicletas y vestuarios. En otra parte del sótano, debajo del hall principal, están situadas las instalaciones de producción eléctrica, climatización y maquinaria separadas del bloque principal, con objeto de evitar la transmisión de posibles vibraciones a las plantas altas.

Las plantas primera y segunda comprenden cuatro comedores, con un total de 744 plazas y cuatro cafeterías capaces para 300 asientos. En la parte central de cada planta está la gran de montaplatos, que asegura una asistencia rápida y eficaz.

La tercera planta está destinada a misiones La tercera planta está destinada a misiones
más nobles y consta de una parte de comedor de dirección, con sus servicios anejos de cocina, de direcion, con sus de salones de conferencias, proyecciones cine de salones de conferencias, proyecciones cinematográficas y exposiciones. El salón de confezas, despacho para el conferenciante y almacén de sillas.

El conjunto del edificio, con su basamento de ladrillo amarillento, sus tres plantas diáfanas y brillantes, sus fachadas laterales con ligera curvatura y el voladizo que lo remata en toda su superficie, resulta nitido, sencillo y de composición elegante y actual.

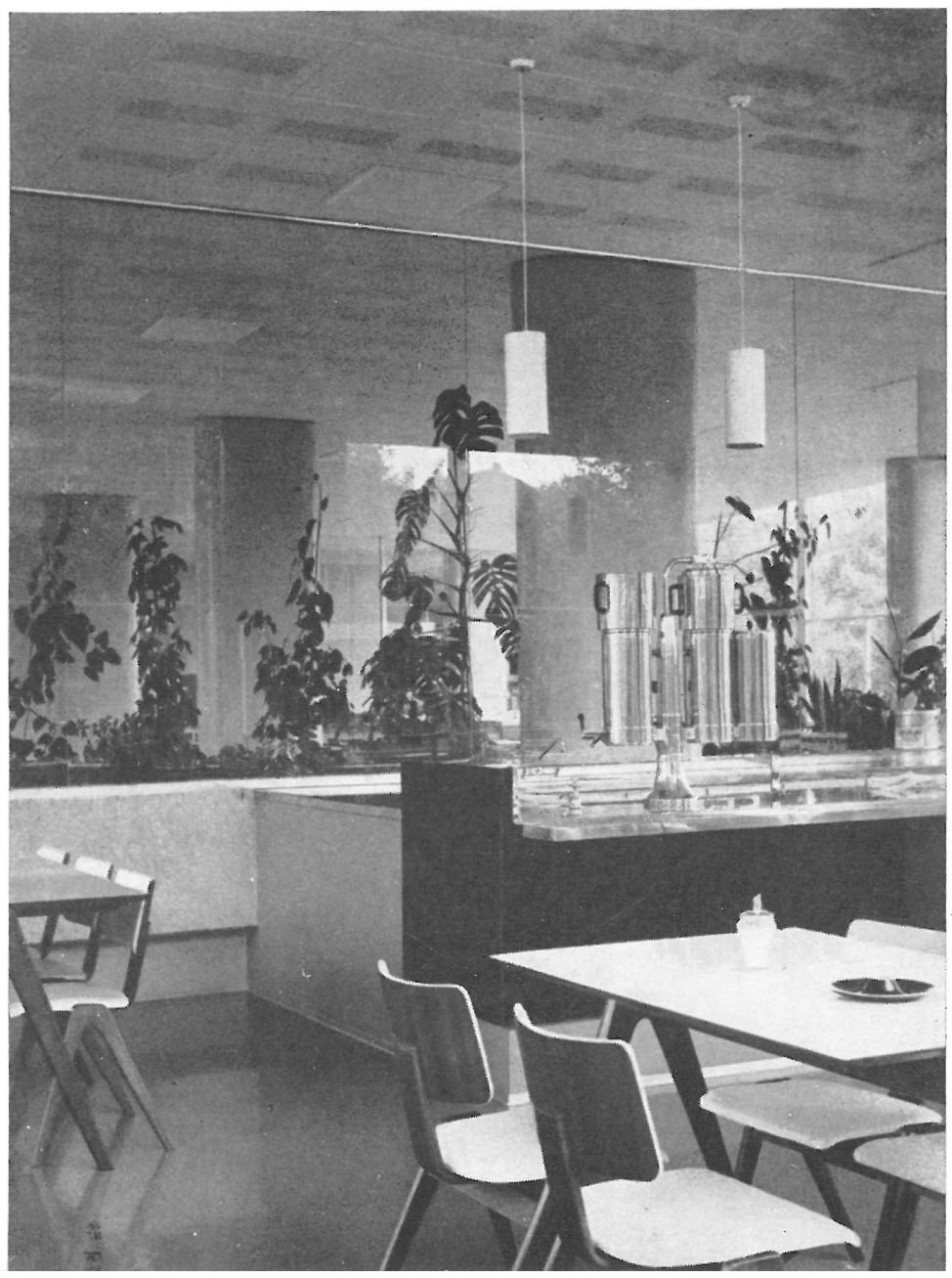

